http://dx.doi.org/10.4314/njt.v37i3.26

\title{
DOUBLE-STATOR SWITCHED FLUX PERMANENT MAGNET MACHINES HAVING LOW ROTOR POLE NUMBERS
}

\author{
C. C. Awah ${ }^{1, *}$ and O. I. Okoro ${ }^{2}$

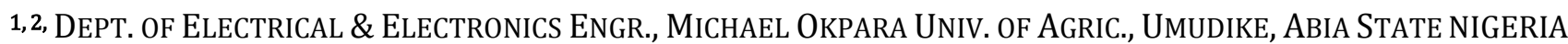 \\ E-mail addresses: ${ }^{1} c c a w a h @ i e e e . o r g,{ }^{2}$ profogbonnayaokoro@ieee.org
}

\begin{abstract}
In this paper, double-stator switched flux permanent magnet (DS-SFPM) machines having low rotor numbers and whose stator teeth and rotor pole numbers are relatively same is investigated. Quantitative comparison of their electromagnetic performance is also given. Two-dimensional finite element (2D-FEA) analysis is employed in the prediction of the developed machines' performance. It is observed that the open circuit flux-linkage waveforms of the analysed machines having odd rotor poles are both symmetrical and sinusoidal in contrast to its even number rotor pole counterparts whose waveforms are asymmetrical, non-sinusoidal and unbalanced. More importantly, the developed machines with odd rotor pole numbers exhibit higher torque density than its even rotor pole equivalents.
\end{abstract}

Keywords: Harmonics, low rotor pole, PM usage, and unbalanced back-EMF.

\section{INTRODUCTION}

Many thanks to the merits of dual-stator permanent magnet (PM) machines over their single-stator counterparts which includes higher power and torque density $[1,2]$, better efficiency and overall performance. A double stator PM machine and magnetic gear are integrated in [1] as a single highperformance system, whose torque production is based on appropriate modulation of the magnetic fields produced by both the armature windings and the permanent magnets on the separate stators. The contributions of the different excitation sources on the machine's performance could be determined by employing the frozen permeability method proposed in [3].

In order to reduce the defects of variable reluctance machine (VRM) which include: high acoustic noise and torque pulsations, a novel doubly salient PM (DSPM) machine having special stator structure is proposed in [4]. Although the proposed DSPM in [4] is capable of producing higher power, torque and better efficiency than the existing VRMs and induction machines, it has limited applications due to its pulsed torque production which depends on the positive and negative injection of currents in accordance with the alignments of the rotor and stator positions. Further work on DSPM machine having simple cylindrical shaped dualstator structure is investigated in [5], however with increased axial length and additional production cost.
Although, the efficiency of the machine in [5] is improved due to the use of high energy magnets, in addition to its enhanced resultant output torque obtained from the combined effect of the two DSPM units, having zero reluctance torque as a result of appropriate phase displacement $(90$ deg. shift) between the two sets; yet the integrated machine is not completely devoid of torque ripple. Moreover, an improved dual-stator machine model having a ringshaped rotor and capable of taking care of the associated voltage and torque ripples of VRM is proposed and analyzed in [6].

It is proven that, the lamination direction of doubly salient machines, in particular, the flux-switching types, plays important role on its overall torque and efficiency performance [7]. Noting that, the axially laminated machine seems to be the best since it has decreased non-linear magnetic saturation compared to the radiallaminated ones.

Similarly, doubly-salient flux-reversal machine with improved design geometry is given in [8], in order to enhance its inherent low power factor owing to its high leakage flux around the air-gap. Furthermore, the withstand capability of the flux reversal machine (FRM) to demagnetization effect is improved by inserting the PMs on the stator teeth in contrast to the surface-mounted type of conventional FRMs [9]. It should be noted that, the modified machine in [9] has improved self-inductance profile for fault tolerant 
applications as well reduced cogging torque relative to the traditional FRMs.

In this work, we investigated and compared the machine performance of double-stator switched flux PM machine having dual excitations as well as low rotor pole numbers whose stator teeth $\left(\mathrm{N}_{\mathrm{s}}\right)$ and rotor pole $\left(\mathrm{N}_{\mathrm{r}}\right)$ numbers are given by $\mathrm{N}_{\mathrm{r}}=\mathrm{N}_{\mathrm{s}} \pm 1$ and $\mathrm{N}_{\mathrm{r}}=\mathrm{N}_{\mathrm{s}} \pm 2$. The analysis includes both the on-load and open-circuit characteristics.

\section{METHODOLOGY}

The machine geometry and every other part of the machine are created using the ANSOFT-MAXWELL FEA software. Note that finer triangular mesh of $0.5 \mathrm{~mm}$ restricted maximum length is built around the air-gap to enhance the accuracy of the results since we adopted the 2D FEA approach in most of the calculations; though, we also employed the 3D FEA analysis for quick comparison of our results in Section 4. It is worth noting that, the used permanent magnet material in this paper is the Neodymium Iron Boron $(\mathrm{NdFeB})$ rareearth type having flux density of $1.2 \mathrm{~T}$ and relative permeability of 1.05. Consequently, Maxwell tensor stress method is adopted in the torque production. The entire calculation is based upon time-stepped transient analysis. An illustrative diagram showing the dimensions of the analyzed machine is shown in Figure 1. It is worth mentioning that, the used rotor and stator materials are laminated steel. The employed winding type is concentrated non-overlapping windings.

The optimum values of the parameters are given in Table 2. Figure 2 shows the 3D mesh plots and flux density distribution (on no-load) of the analyzed machine. It is obvious from the flux density distribution of Figure 2 (b) that the inner and outer stator teeth of the analyzed machine would undergo quicker saturation than every other part of the machine.

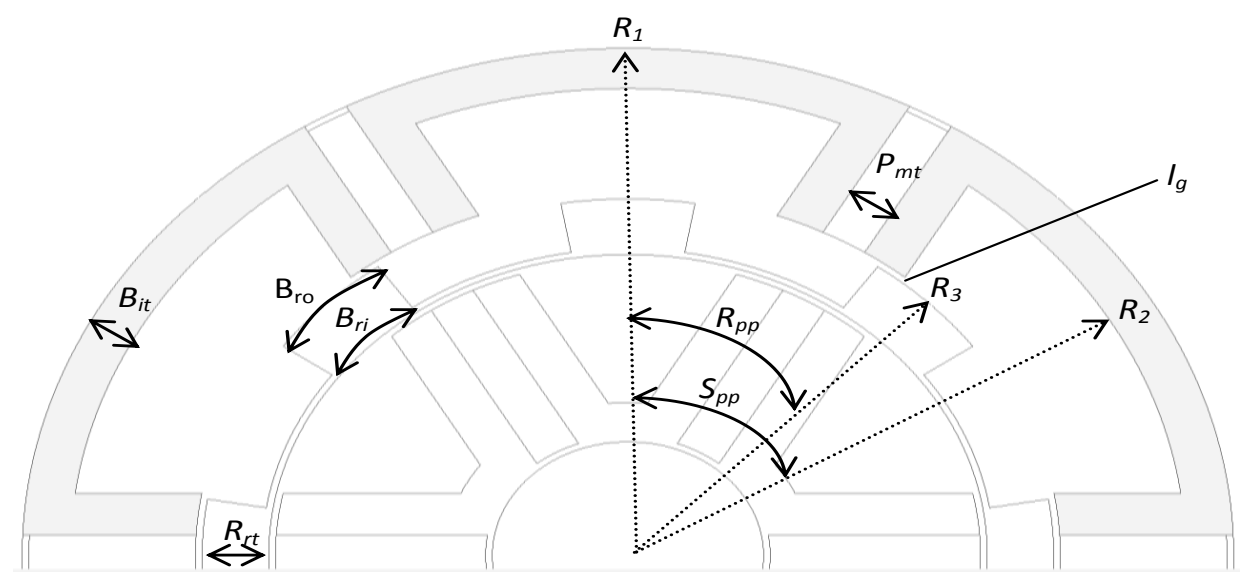

Figure 1: Illustration of the analyzed DS-SFPM dimensions.

The employed analytical dimensions/parameters are as follows:

$R_{1}=$ outer stator diameter $=45 \mathrm{~mm}, S_{p p}=$ Stator pole pitch $=360 \% / N_{s o}$, where $N_{s o}=$ Outer stator pole number; $N_{s i}=$ Inner stator pole number; $N_{s i}=N_{s o} ; R_{p p}=$ Rotor pole pitch $=360 \% / N_{r} ; N_{r}=$ Number of rotor poles; $R_{r t}=$ Rotor radial thickness; $B_{i t}=$ Back-iron thickness $=R_{1}-R_{2} ; P_{m t}=$ Permanent magnet thickness; $P_{m h}=$ PM height; $B_{r o}=$ Rotor outer width= Rotor pole pitch ${ }^{*} K_{2} ; B_{r i}=$ Rotor inner width $=$ Rotor pole pitch ${ }^{*} K_{1}$, where $K_{1}$ and $K_{2}$ varies between $0.1-0.9$, depending on the value of optimum average torque; Air-gap length, $I_{g}=0.5 \mathrm{~mm} ; S p l i t$ ratio, $S_{r}=$ $\left(R_{3}+0.5^{*} / g\right) / R_{1} ;$ Speed, $S=400 \mathrm{rpm} ;$ Omega $=\left(\right.$ Speed $^{*} N_{r}{ }^{*} 2^{*}$ pi $) / 60 ;$ Time, $T=2^{*}$ pi/Omega, Step size, $S_{z}=$ Time/60; and Assumed packing factor, $\mathrm{K}_{\mathrm{pf}}=0.6$.

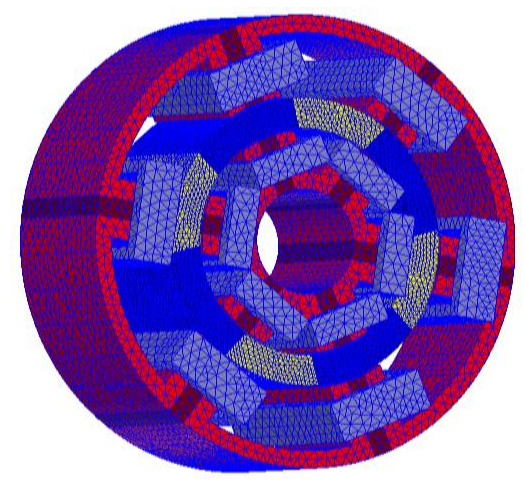

(a) Mesh plots

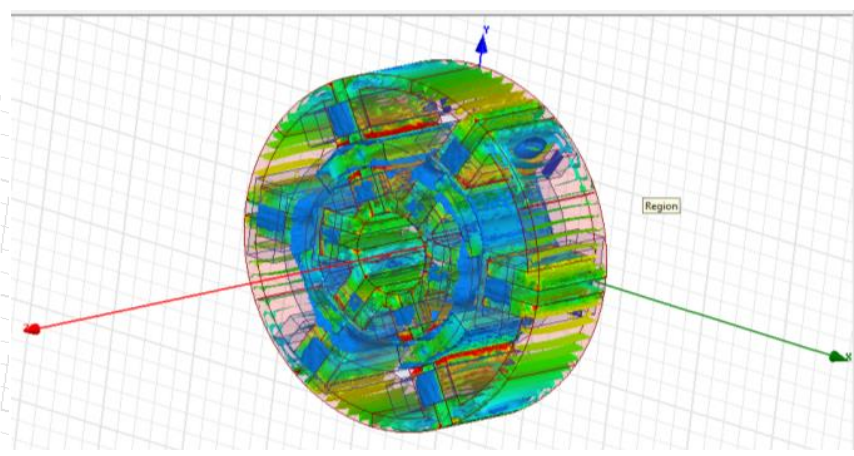

(b) No load flux density profile

Figure 2: 3D mesh and flux density distribution of the analyzed machine. 


\section{MACHINE DESCRIPTION}

Figure 3 shows the schematic diagram of the developed DS-SFPM machine having 4-rotor iron pieces, held together by iron bridges of $0.5 \mathrm{~mm}$ thickness. It consists of two-separate doubly-salient pole stators having dual excitation sources. The outer stator of the developed DS-SFPM machine is similar to that of switched reluctance machine (SRM). However, the torque production in the analyzed machine is essentially based on the principles of flux-switching effects. The coil EMF phasors and its corresponding winding configurations of the analyzed machines are shown in Figure 4.

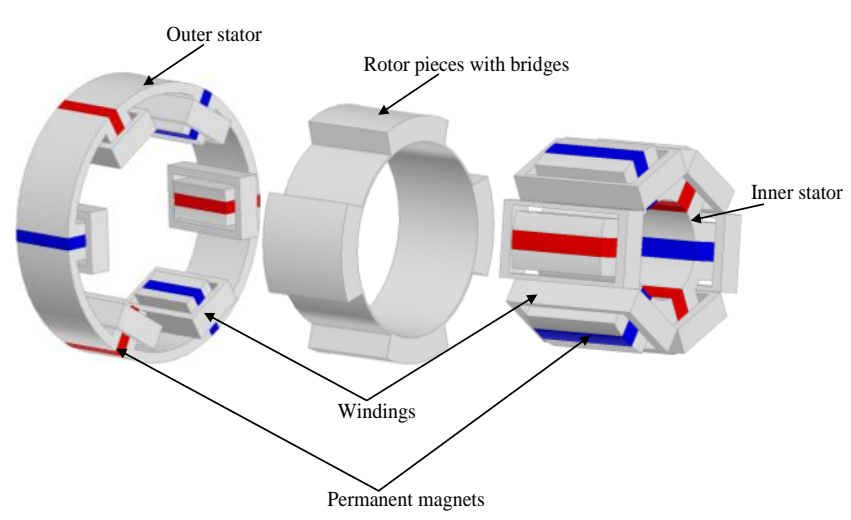

Figure 3: Schematic diagram of the developed DS-SFPM machine.

Note that, the electrical angle of the developed machine is a product of its mechanical angular displacement and their respective rotor pole number. The adopted fluxconcentration technique in this study would help to increase the air-gap flux density thereby compensating for the leakage flux of the stator excitations.

In general, the possible stator and rotor pole number arrangement of the developed machines is given in equation (1).

$$
N_{r}=k N_{s} \pm j
$$

where $k$ and $j=$ integers $1,2 \ldots, N_{r}$ and $N_{s}$ are the numbers of rotor- and stator-poles, respectively.

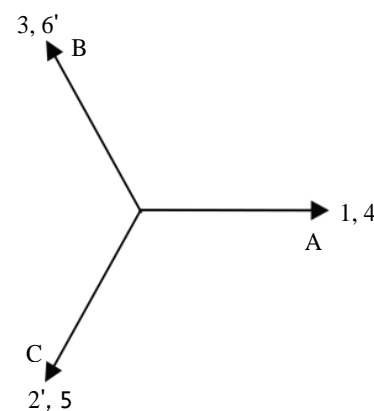

(a) 4-rotor-pole

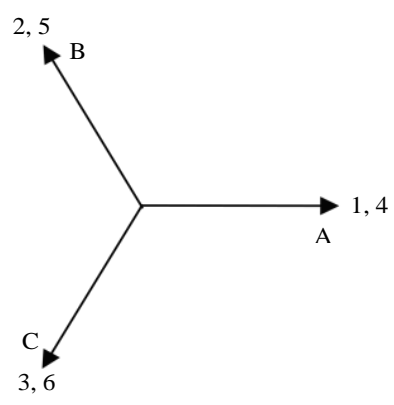

(b) 5-rotor-pole
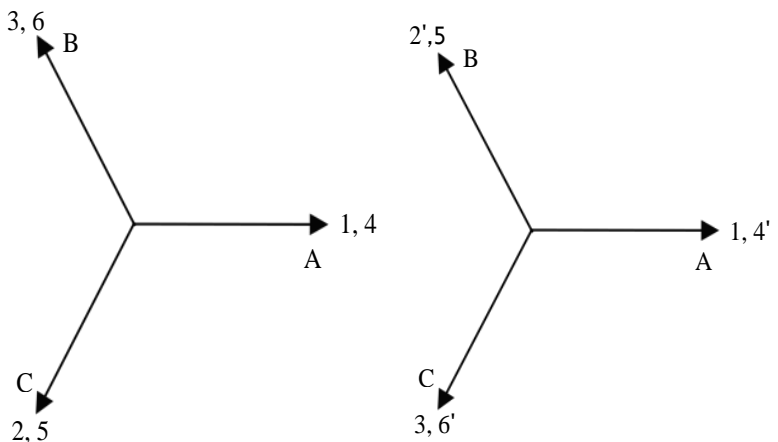

(c) 7-rotor-pole

(d) 8-rotor-pole

Figure 4: Coil EMF phasors and winding configurations of investigated machines.

\section{RESULTS}

The no-load flux-linkage of the investigated machines is given in Figure 5. It is obvious that, the flux-linkage waveforms of the analyzed machines having $\mathrm{N}_{\mathrm{r}}=$ even number are both unbalanced and non-sinusoidal unlike the waveforms of the machines having odd rotor pole numbers whose waveforms are sinusoidal and symmetrical as well as balanced about the rotor position. This is because of the existence of even order harmonics in the EMF spectra of the even rotor pole machines.

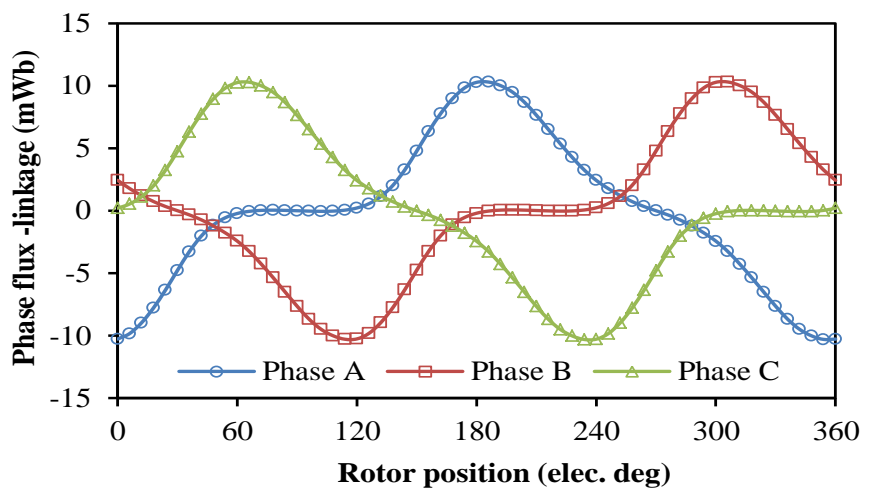

(a) 4-rotor pole

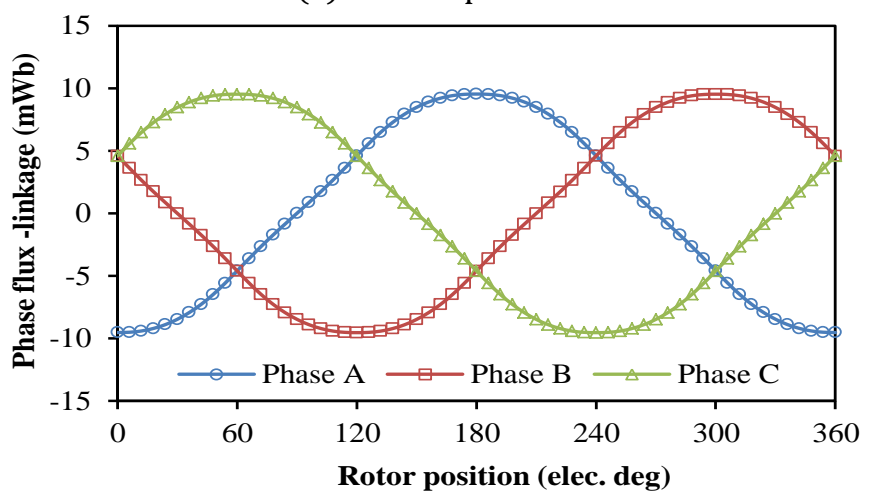

(b) 5-rotor pole 


\section{Double-Stator Switched Flux Permanent Magnet Machines having Low Rotor Pole Numbers C. C. Awah \& O. I. Okoro}

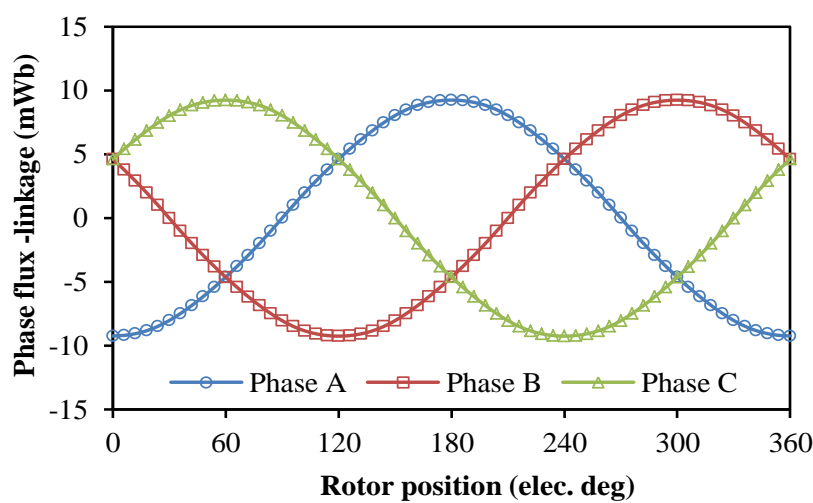

(c) 7-rotor pole

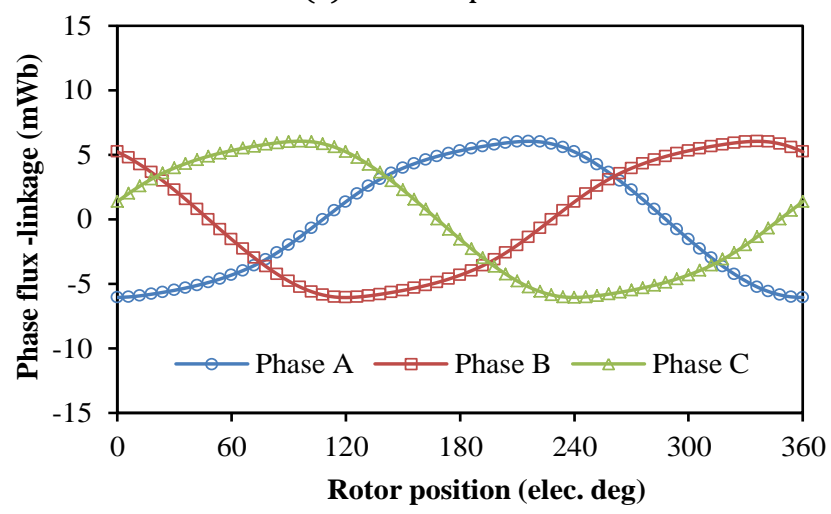

(d) 8-rotor-pole

Figure 5: Open-circuit variation of phase flux-linkage with rotor position.

The distribution factor of the investigated machines can be calculated by equation (2),

$$
D_{f}=\frac{\sin \left(\frac{N_{E} h y}{2}\right)}{N_{E} \sin \left(\frac{h y}{2}\right)}
$$

where $N_{E}$ is the number of EMF vectors, $\gamma$ is the angle between two adjacent vectors, and $h$ is the harmonic order. Similarly, the pitch factor and the winding factor are given in (3) and (4), respectively [10].

$$
\begin{gathered}
P_{r}=\cos \left(p i . h\left(\frac{N_{r}}{N_{s}}-1\right)\right) \\
W_{f}=D_{f} P_{f}
\end{gathered}
$$

Moreover, the computed values of the distribution, pitch and winding factors of the analyzed machines from fundamental up to the $13^{\text {th }}$ harmonic order are given in Table 1. However, the winding factor could also be multiplied by a skew factor to account for the situation where the rotor is skewed; although, this condition is not applicable in this paper. Note that, the distribution factor of a six-stator pole PM machine having possible rotor combinations of 4-, 5-, 7-, and 8poles are all equal to 1 . This is so, because the compared machines have similar number of EMF vectors on the same phase as seen from phasors of Figure 4. It should be noted that the fundamental values of both the pitch factor and the winding factor of the machines are larger in the machine topologies having $\mathrm{N}_{\mathrm{r}}=\mathrm{N}_{\mathrm{s}} \pm 1$ compared to those with $\mathrm{N}_{\mathrm{r}}=\mathrm{N}_{\mathrm{s}} \pm 2$. A detailed study on how to estimate the winding factors of fluxswitching PM machines having different number of

\begin{tabular}{|c|c|c|c|c|c|c|c|c|c|c|c|c|c|}
\hline \multicolumn{14}{|c|}{ Pitch factor } \\
\hline Harmonic order, $\mathrm{h}$ & 1 & 2 & 3 & 4 & 5 & 6 & 7 & 8 & 9 & 10 & 11 & 12 & 13 \\
\hline 4-rotor pole & 0.50 & -0.50 & -1.00 & -0.50 & 0.50 & 1.00 & 0.50 & -0.50 & -1.00 & -0.50 & 0.50 & 1.00 & 0.50 \\
\hline 5-rotor pole & 0.87 & 0.50 & 0.00 & -0.50 & -0.87 & -1.00 & -0.87 & -0.50 & 0.00 & 0.50 & 0.87 & 1.00 & 0.87 \\
\hline 7-rotor pole & 0.87 & 0.50 & 0.00 & -0.50 & -0.87 & -1.00 & -0.87 & -0.50 & 0.00 & 0.50 & 0.87 & 1.00 & 0.87 \\
\hline 8-rotor pole & 0.50 & -0.50 & -1.00 & -0.50 & 0.50 & 1.00 & 0.50 & -0.50 & -1.00 & -0.50 & 0.50 & 1.00 & 0.50 \\
\hline & & & & & & & & & & & & & \\
\hline \multicolumn{14}{|c|}{ Distribution factor } \\
\hline Harmonic order, $\mathrm{h}$ & 1 & 2 & 3 & 4 & 5 & 6 & 7 & 8 & 9 & 10 & 11 & 12 & 13 \\
\hline 4-rotor pole & 1.00 & 1.00 & 1.00 & 1.00 & 1.00 & 1.00 & 1.00 & 1.00 & 1.00 & 1.00 & 1.00 & 1.00 & 1.00 \\
\hline 5-rotor pole & 1.00 & 1.00 & 1.00 & 1.00 & 1.00 & 1.00 & 1.00 & 1.00 & 1.00 & 1.00 & 1.00 & 1.00 & 1.00 \\
\hline 7-rotor pole & 1.00 & 1.00 & 1.00 & 1.00 & 1.00 & 1.00 & 1.00 & 1.00 & 1.00 & 1.00 & 1.00 & 1.00 & 1.00 \\
\hline 8-rotor pole & 1.00 & 1.00 & 1.00 & 1.00 & 1.00 & 1.00 & 1.00 & 1.00 & 1.00 & 1.00 & 1.00 & 1.00 & 1.00 \\
\hline \multicolumn{5}{|c|}{ Winding factor } & & $\mathrm{g}$ factor & & & & & & & \\
\hline Harmonic order, h & 1 & 2 & 3 & 4 & 5 & 6 & 7 & 8 & 9 & 10 & 11 & 12 & 13 \\
\hline 4-rotor pole & 0.50 & -0.50 & -1.00 & -0.50 & 0.50 & 1.00 & 0.50 & -0.50 & -1.00 & -0.50 & 0.50 & 1.00 & 0.50 \\
\hline 5-rotor pole & 0.87 & 0.50 & 0.00 & -0.50 & -0.87 & -1.00 & -0.87 & -0.50 & 0.00 & 0.50 & 0.87 & 1.00 & 0.87 \\
\hline 7-rotor pole & 0.87 & 0.50 & 0.00 & -0.50 & -0.87 & -1.00 & -0.87 & -0.50 & 0.00 & 0.50 & 0.87 & 1.00 & 0.87 \\
\hline 8-rotor pole & 0.50 & -0.50 & -1.00 & -0.50 & 0.50 & 1.00 & 0.50 & -0.50 & -1.00 & -0.50 & 0.50 & 1.00 & 0.50 \\
\hline
\end{tabular}
phases and poles are given in [10].

Table 1: Distribution factor, pitch factor, and winding factors of the analyzed DS-SFPM machine 
A two-dimensional and three dimensional finite element comparison of the Phase A flux-linkages of the analyzed machines are depicted in Figure 6. There is significant difference between the 2D FEA and 3D FEA predicted results owing to the large end-winding effect which is absent in the case of 2D analysis. Large endeffect phenomenon is usually common amongst fluxswitching PM machines, as mentioned in [11].

Similarly, the induced electromotive force (EMF) waveforms of the analyzed double stator machines on

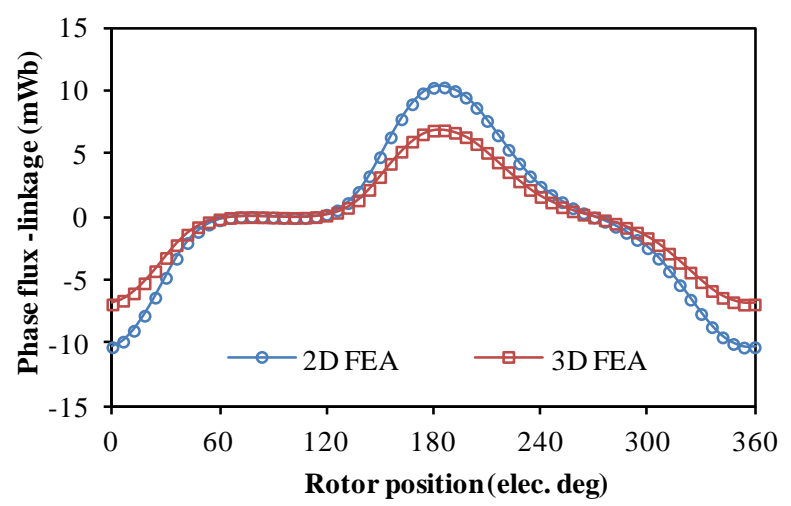

(a) 4-rotor-pole

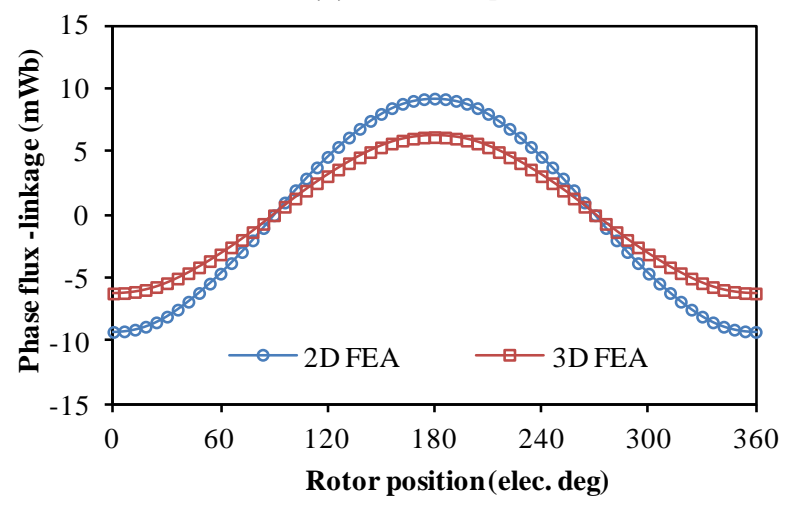

(c) 7-rotor-pole open circuit condition are shown in Figures (7-10). It should be noted that, although the back-EMF waveforms are symmetrical about the rotor position, they are far away from sinusoidal shapes, especially the waveforms of the even rotor pole machines. The implication being that the even rotor pole machines would be difficult to control in terms of drives. The corresponding spectra also show that the developed machines contain some level of harmonics.

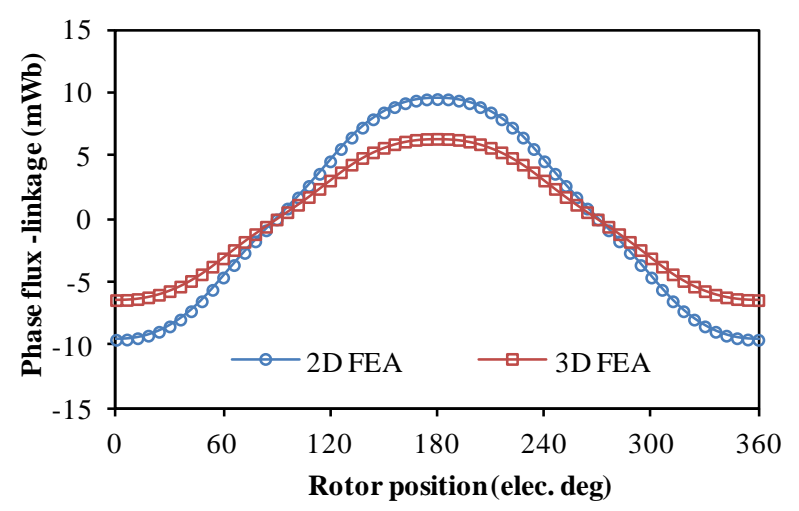

(b) 5-rotor-pole

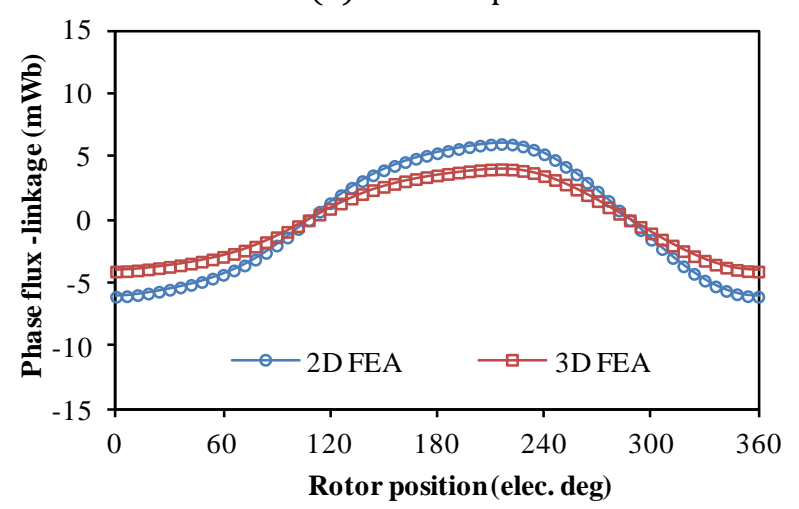

(d) 8-rotor-pole

Figure 6: Comparison of Phase A flux-linkage, no load.

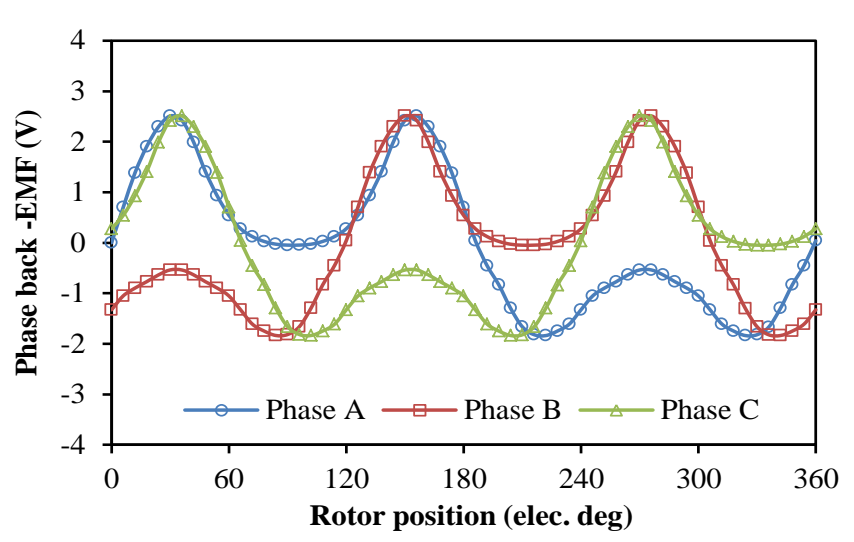

(a) Waveforms

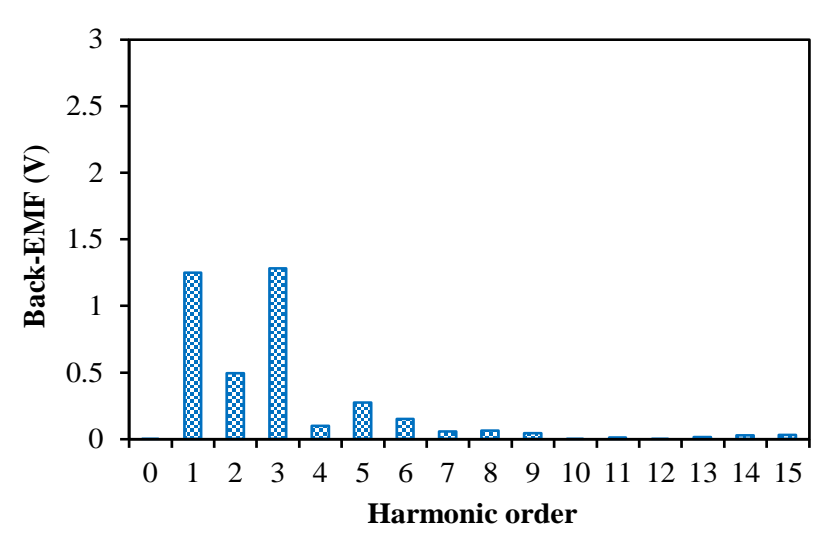

(b) Spectra

Figure 7: Open-circuit variation of back-EMF with rotor position, 4-rotor pole (400rpm). 


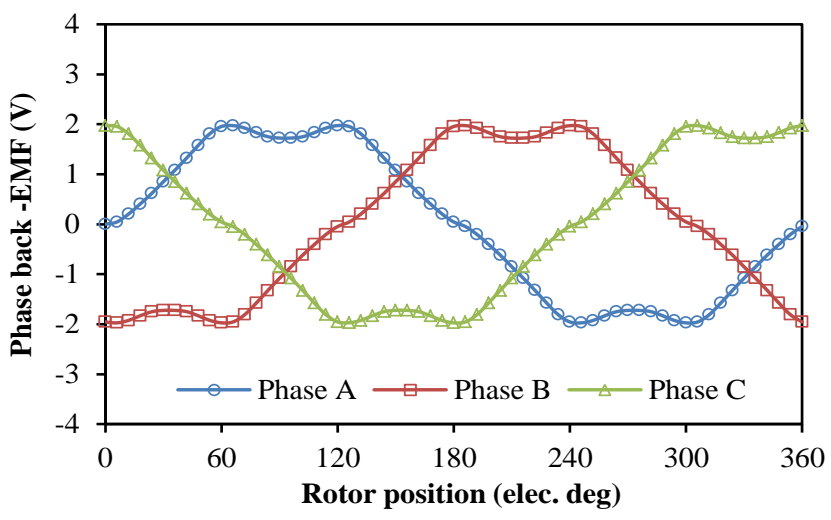

(a) Waveforms

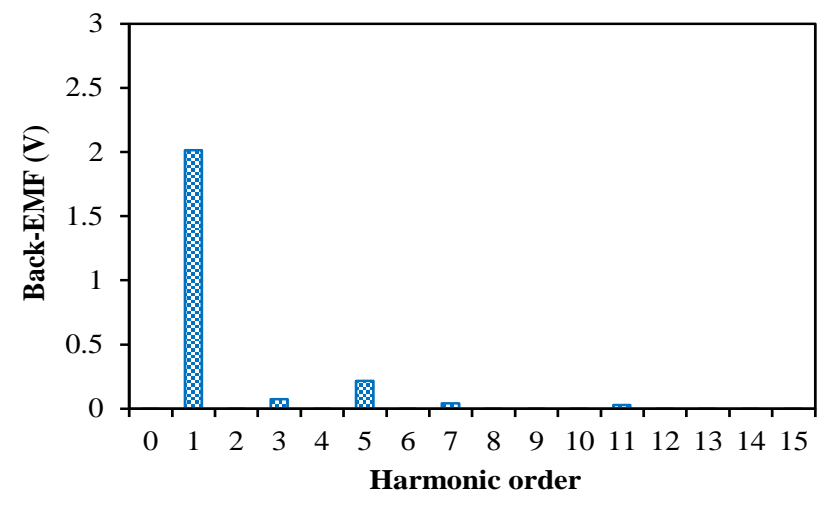

(b) Spectra

Figure 8: No-load variation of back-EMF with rotor position, 5-rotor pole (400rpm).

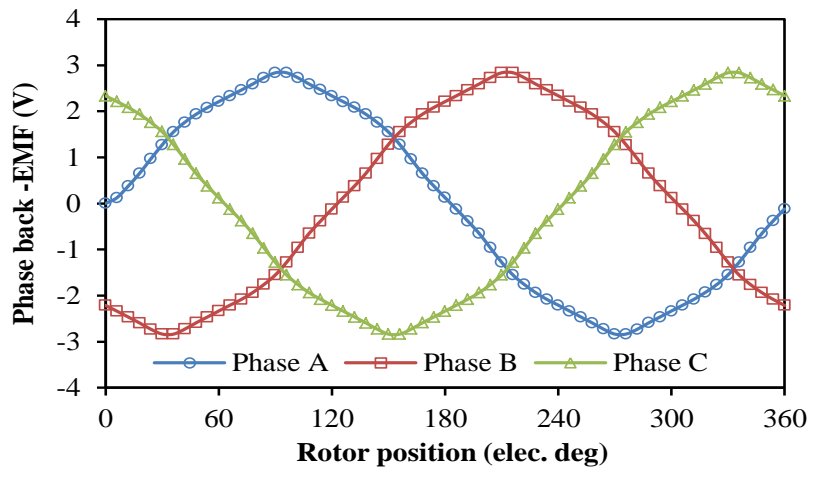

(a) Waveforms

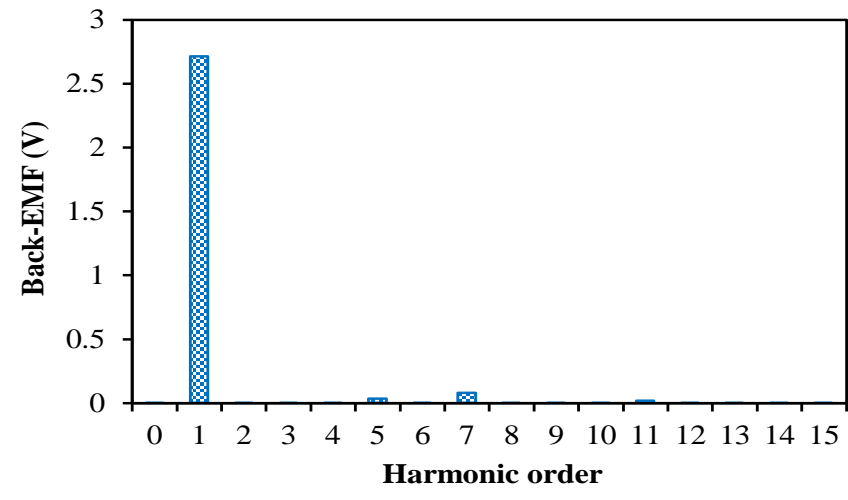

(b) Spectra

Figure 9: Open-circuit variation of back-EMF with rotor position, 7-rotor pole (400rpm).

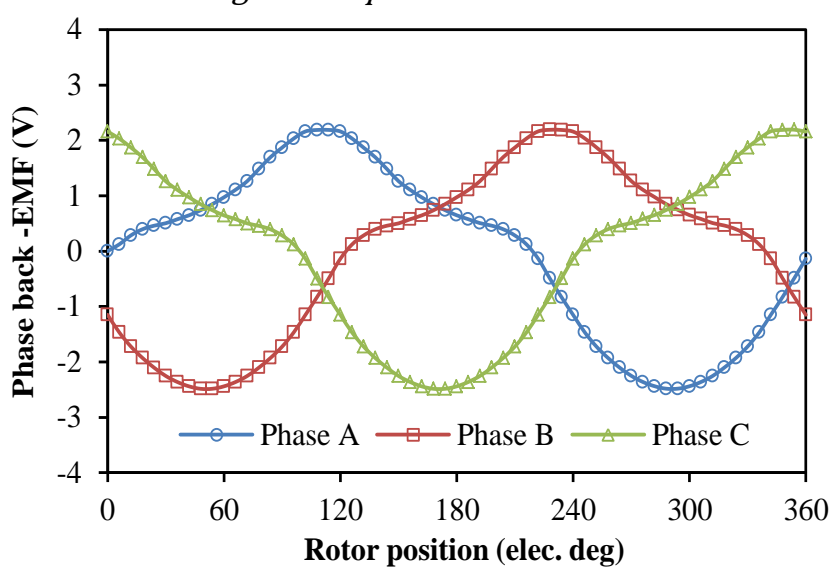

(a) Waveforms

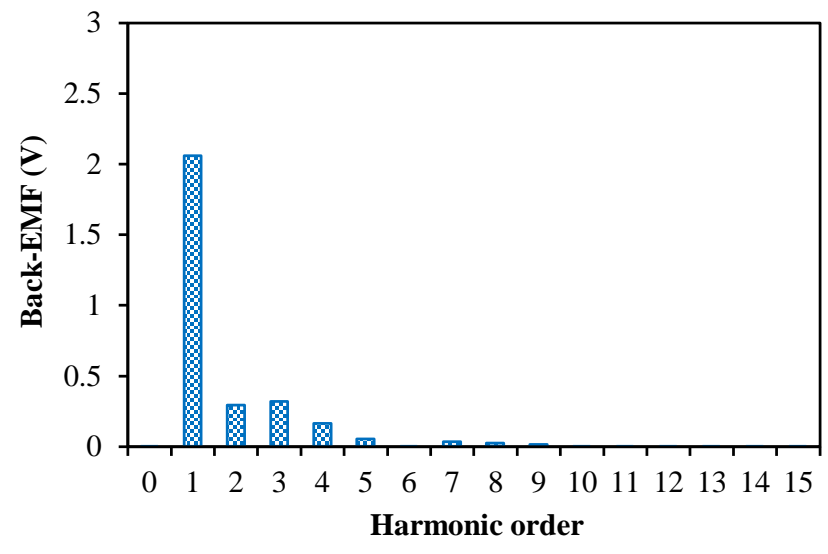

(b) Spectra

Figure 10: No-load variation of back-EMF with rotor position, 8-rotor pole (400rpm).

Furthermore, 3D and 2D FEA Phase A back-EMF waveforms of the analyzed machines are compared in Figure 11. It could also be seen that there is noticeable difference in magnitude between the 2D and 3D predictions. Moreover, the analyzed double stator PM machine is associated with flux leakage both around the stator yoke and the air-gap. This will directly affect the overall output torque of the machine since the electromotive force is a time-variation of the developed flux-linkage and invariably the electromagnetic torque is a function of the induced electromotive force.
The output torque waveforms and spectra of the investigated machines are depicted in Figure 12. Note that, the 7-rotor pole machine has the largest amount of torque. It is worth noting that, the 4- and 8-rotor pole machines have dominant harmonic order of multiples of three as seen in the torque harmonic spectra of Figure 12(b). Similarly, the torque versus current, current-angle and copper loss curves of the analyzed DS-SFPM machines are shown in Figures (1315). It should be noted, that the 5-pole and 8-pole machines have similar saturation curves within the rated load conditions. 
Further, the optimum values of the main machine parameters are listed in Table 2.

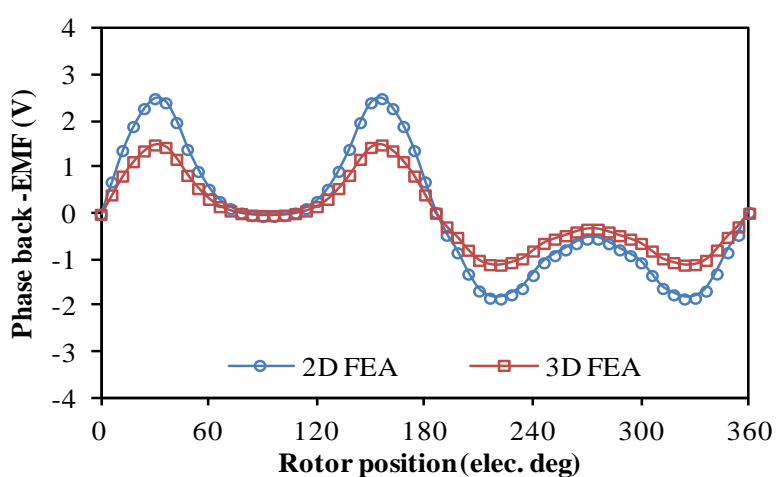

(a) 4-rotor-pole

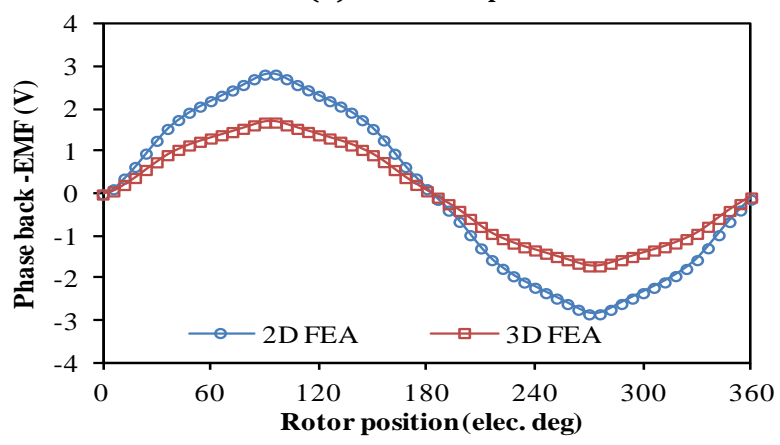

(c) 7-rotor-pole

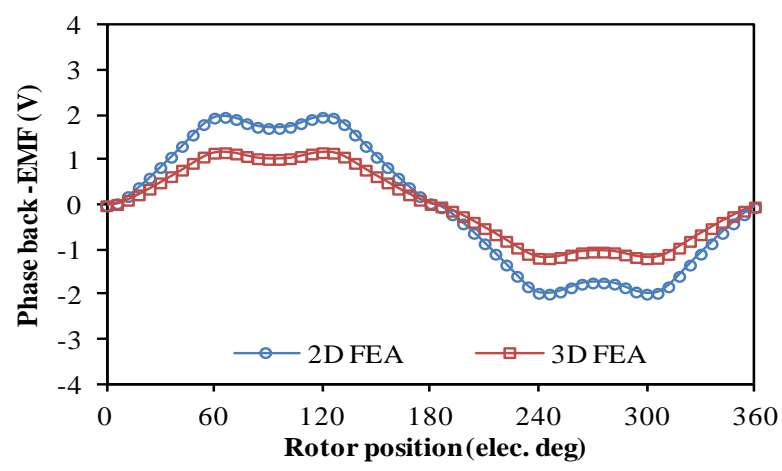

(b) 5-rotor-pole

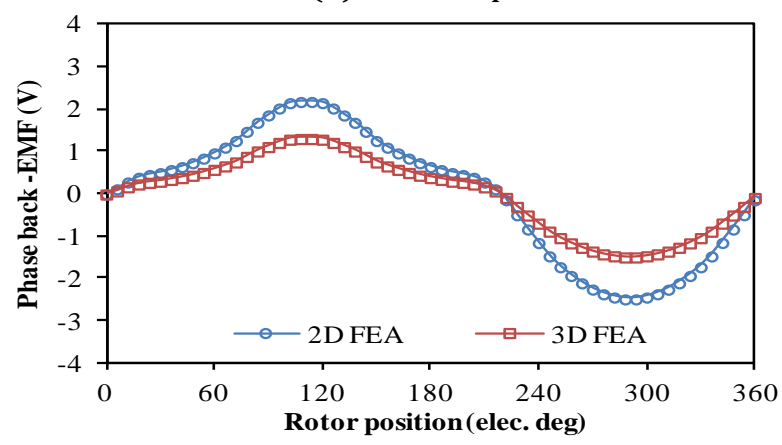

(d) 8-rotor-pole

Figure 11: Comparison of Phase A back-EMF at $400 \mathrm{rpm}$.

Table 2: Parameters of Developed Double-Stator PM Machines

\begin{tabular}{|c|c|c|c|c|}
\hline Parameter & Value & & & \\
\hline Outer stator slot number & 6 & & & \\
\hline Inner stator slot number & 6 & & & \\
\hline Air-gap length (mm) & 0.5 & & & \\
\hline Axial length (mm) & 25 & & & \\
\hline Machine outer diameter (mm) & 90 & & & \\
\hline Outer stator turns/coil & 24 & & & \\
\hline Inner stator turns/coil & 12 & & & \\
\hline Total number of turns/phase & 72 & & & \\
\hline PM remanence $(\mathrm{T})$ & 1.2 & & & \\
\hline Rotor pole number, $N_{r}$ & 4 & 5 & 7 & 8 \\
\hline Split ratio & 0.67 & 0.59 & 0.55 & 0.57 \\
\hline PM thickness, $P_{m t}(\mathrm{~mm})$ & 3.87 & 3.69 & 3.63 & 3.97 \\
\hline Back-iron thickness, $B_{i t}(\mathrm{~mm})$ & 3.46 & 3.53 & 3.57 & 3.39 \\
\hline Torque density (k.Nm/m³) & 8.49 & 14.54 & 19.12 & 14.31 \\
\hline Rotor radial thickness (mm) & 7 & 7 & 6 & 6 \\
\hline $\begin{array}{l}\text { Outer rotor pole width/pitch } \\
\text { ratio }\end{array}$ & 0.4 & 0.4 & 0.4 & 0.4 \\
\hline $\begin{array}{l}\text { Inner rotor pole width /pitch } \\
\text { ratio }\end{array}$ & 0.5 & 0.5 & 0.4 & 0.4 \\
\hline
\end{tabular}

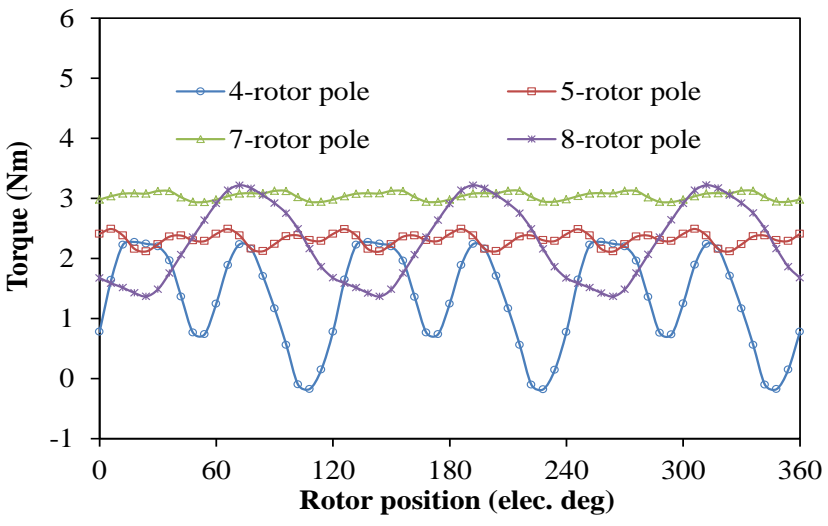

(a) Waveforms

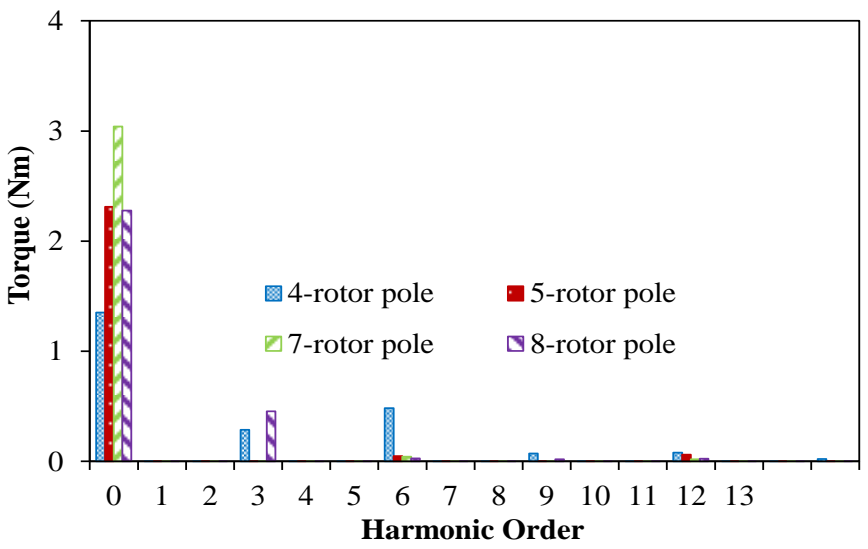

(b) Spectra

Figure 12: Torque versus rotor position, (at fixed copper loss of $30 \mathrm{~W}$ ). 
It is worth mentioning that, the machine topologies having higher fundamental winding factor would also have larger average value of both back-EMF and consequently output torque as seen from Table 1 and Figures 11 and 12 . Note that, the machines having even number of rotor poles exhibit enormous torque ripples as could be seen from Figure 12, likely due to the presence of the $3^{\text {rd }}$ harmonic component. The effect of the larger pitch factor and winding factor of the machines with odd number of rotor poles is also reflected on Figure 13, especially within twice the rated current of 15A. Thus, the higher the winding factor, the better its overall performance.

Figure 14 clearly shows that the maximum average torque would be obtained when the rotor aligns with the direct axis of the machine. It also depicts that the compared machines have negligible reluctance torque since maximum torque is realized at the zero phase current angle position. Also, it could be inferred from Figure 16 that, the odd-rotor pole number machines seem to be the most promising options in cost-sensitive applications since it produces larger average torque and utilizes less magnet volume for the same machine size.

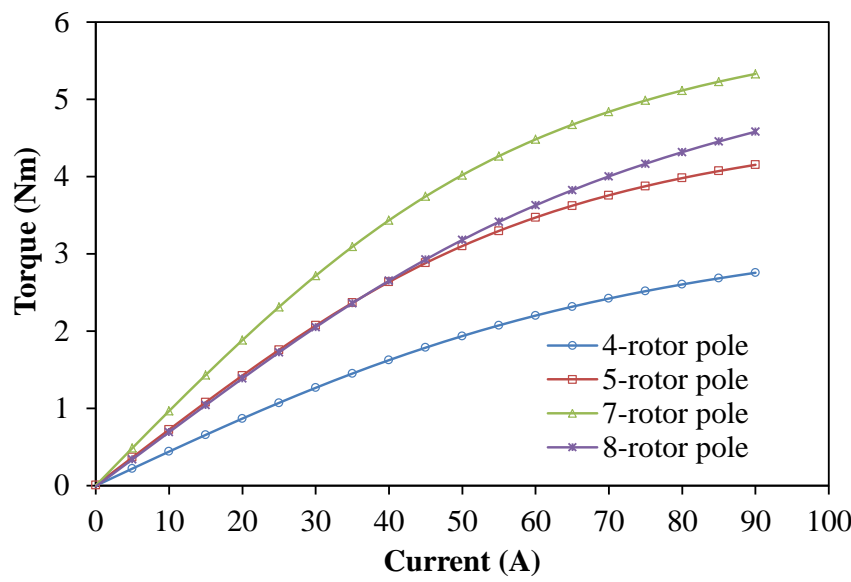

Figure 13: Comparison of torque against current.

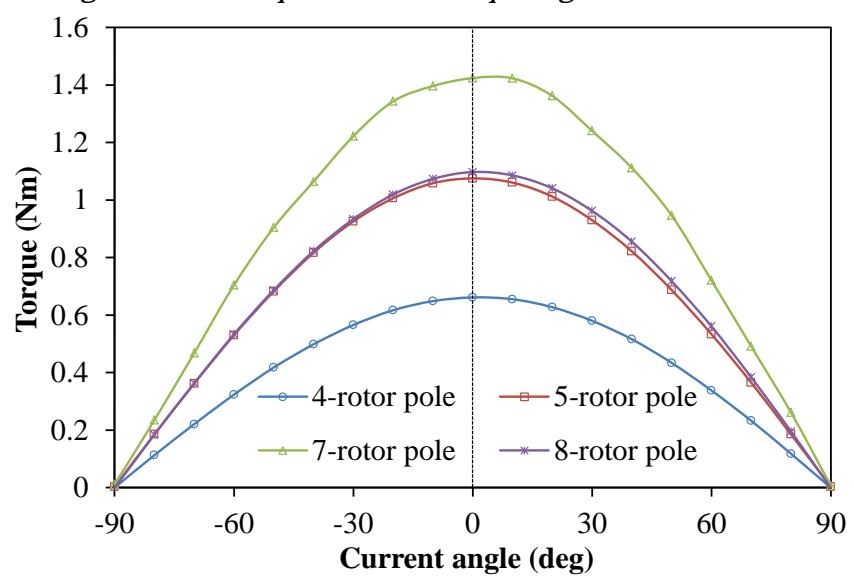

Figure 14: Comparison of torque against current angle,

$$
I_{\max }=15 \mathrm{~A} \text {. }
$$

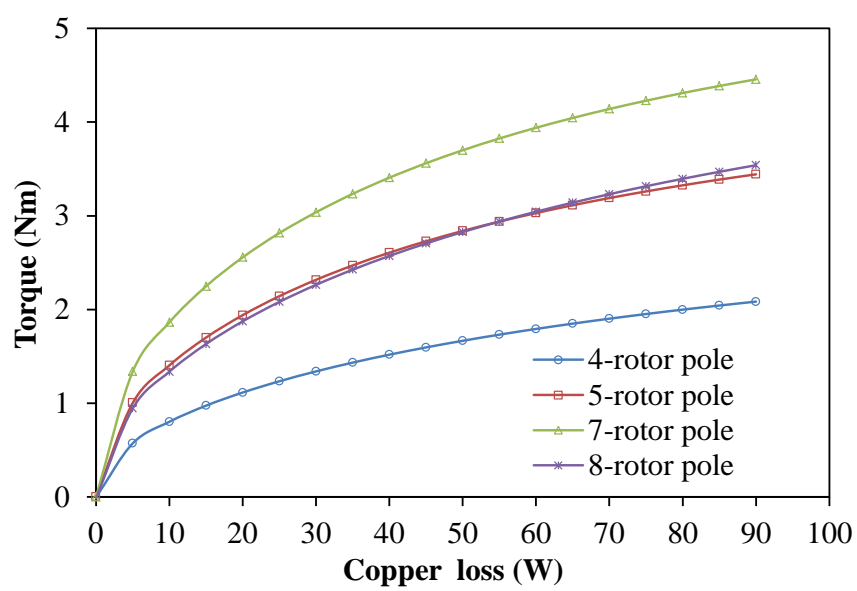

Figure 15: Comparison of torque against copper loss.

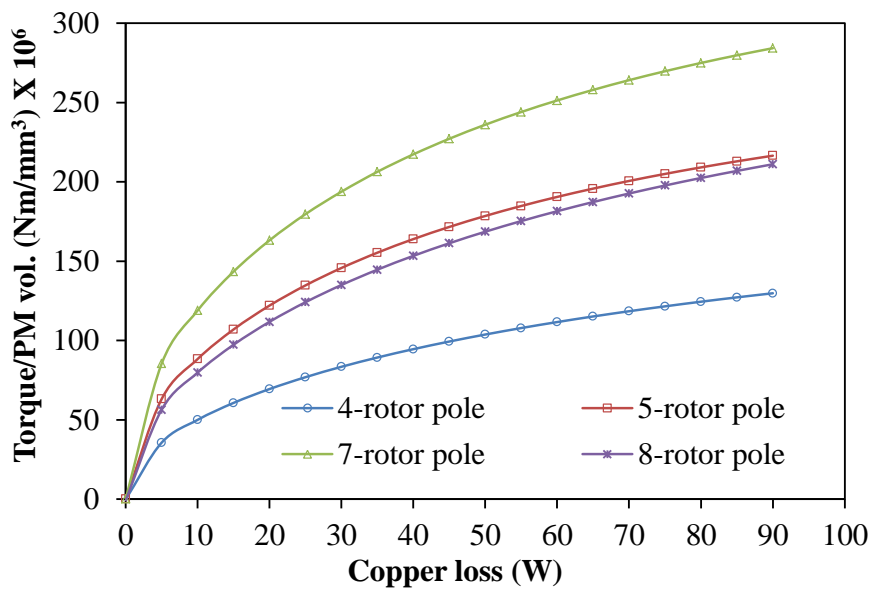

Figure 16: Variation of torque per PM usage versus copper loss.

\section{CONCLUSION}

Double-stator PM machines having low rotor pole numbers are presented. The analysis show that the machines having $\mathrm{N}_{\mathrm{r}}=\mathrm{N}_{\mathrm{s}} \pm 1$ exhibit higher and better flux-linkage and EMF waveforms than their corresponding machines having $\mathrm{N}_{\mathrm{r}}=\mathrm{N}_{\mathrm{s}} \pm 2$, owing to the inherent high harmonic contents of the latter type of machines. Further, we observed that the investigated machines would have negligible reluctance torque. Moreover, the torque density of the machines with odd rotor pole numbers are quite larger than their even rotor pole counterparts, in addition, with lesser PM usage. Above all, the developed 7-rotor pole machine has the largest torque density in this study.

\section{ACKNOWLEDGEMENT}

The first author would like to thank The Commonwealth Scholarship Commission, UK for the sponsorship to run a PhD programme at The University of Sheffield, UK, during which period this research was carried out. 


\section{REFERENCES}

[1] C. Liu, K. T. Chau, and Z. Zhang, "Novel design of double-stator single-rotor magnetic-geared machines," IEEE Trans. Magn., vol. 48, no. 11, pp. 4180-4183, Nov. 2012.

[2] C. Feng, X. Jing, G. Bin, C. Shukang, and Z. Jiange, "Double-stator permanent magnet synchronous in-wheel motor for hybrid electric drive system," IEEE Trans. Magn., vol. 45, no. 1, pp. 278-281, Jan. 2009.

[3] J.A. Walker, D.G. Dorrell, and C. Cossar, "Fluxlinkage calculation in permanent-magnet motors using the frozen permeabilities method," IEEE Trans. Magn., vol. 41, no. 10, pp. 3946-3948, Oct. 2005.

[4] Y. Liao, F. Liang, T.A. Lipo, "A novel permanent magnet motor with doubly salient structure," IEEE Trans Ind. Appli., vol. 31, no. 5, pp. 10691078, Sept./Oct. 1995.

[5] X. Luo, D. Qin, and T.A. Lipo, "A novel two phase doubly salient permanent magnet motor," in IEEE Proc. Ind. Appli.. Conf, pp. 808-815, vol. 2, 1996.

[6] Z. Zhang, Y. Zhou and Y. Yan, "Feature investigation of a new dual-stator doubly salient brushless DC generator with and without rotoryoke," in Proc. Int. Conf. Electr. Mach. Sys., Busan, Korea, pp. 1026-1031, Oct. 2013.

[7] W. Xu, J. Zhu, Y. Zhang, Y. Guo, and G. Lei, “New axial laminated-structure flux-switching permanent magnet machine with $6 / 7$ poles," IEEE Trans. Magn., vol. 47, no. 10, pp. 2823-2826, Oct. 2011.

[8] T.H. Kim and J. Lee, "A study of the design for the flux reversal machine," IEEE Trans. Magn., vol. 40, no. 4, pp. 2053-2055, Jul. 2004.

[9] T.H. Kim, "A study on the design of an insetpermanent-magnet-type flux-reversal machine," IEEE Trans. Magn., vol. 45, no. 6, pp. 2859-2862, Jun. 2009.

[10] J. T. Chen, and Z. Q. Zhu, "Winding configurations and optimal stator and rotor pole combination of flux switching PM brushless AC machines," IEEE Trans. Energy Convers., vol. 25, no. 2, pp. 293-302, Jun. 2010.

[11] Z.Q. Zhu, J. T. Chen, Y. Pang, D. Howe, S. Iwasaki, and R. Deodhar, "Analysis of a novel multi-tooth flux-switching PM brushless AC machine for high torque direct-drive applications," IEEE Trans. Magn., vol. 44, no. 11, pp. 4313-4316, Nov. 2008. 